\title{
Tumor progression mechanisms: Insights from the central immune regulation of tissue homeostasis (Review)
}

\author{
NATALYA LISOVSKA $^{1}$ and NASRULLA SHANAZAROV ${ }^{2}$ \\ ${ }^{1}$ Department of Chemotherapy, Center of Oncology, Cyber Clinic of Spizhenko, \\ Kyiv 08112, Ukraine; ${ }^{2}$ Department of General Surgery, Medical Center Hospital \\ of The President's Affairs Administration of The Republic of Kazakhstan, \\ Astana 010000, Republic of Kazakhstan
}

Received February 16, 2018; Accepted March 7, 2019

DOI: $10.3892 / \mathrm{ol} .2019 .10218$

\begin{abstract}
Knowledge of the mechanisms underlying the spread of cancer at the cellular and molecular levels is expanding rapidly. However, the central regulators governing the initiation and the rate of tumor growth remain poorly established. The fundamental principles of innate and adaptive immunity may explain how immune cells generate a specific response to tumor tissue. In the current review, the functional features of the immune system that contribute to the maintenance of normal tissue homeostasis, as well as their disruption in malignant transformations, were analyzed. Experimental and clinical studies previously demonstrated the involvement of regulatory T-cells in the process of tumor metastasis in a tissue-specific manner. An understanding of the cross talk between lymphoid and tumor cells may provide an insight into cancer evolution in terms of the mechanisms of T-cell competency formation. Elucidating the mechanisms of tumor progression via central immune regulation has implications for the development of novel therapeutic agents that target immune checkpoints.
\end{abstract}

\section{Contents}

1. Introduction

2. Data sources and searches

Correspondence to: Dr Natalya Lisovska, Department of Chemotherapy, Center of Oncology, Cyber Clinic of Spizhenko, 21 Sobornaya Street, Kapitanovka, Kyiv 08112, Ukraine

E-mail: lisovska67@gmail.com

Abbreviations: TH, tissue homeostasis; T-reg, thymically derived regulatory cell; TCR, T-cell receptor

Key words: tumor spread, tissue homeostasis, immune regulation, regulatory $\mathrm{T}$ cells
3. Central immune regulation in maintaining homeostasis of normal tissue

4. Immune regulation in case of tumor tissue manifestation and metastatic spread

5. Conclusion

\section{Introduction}

Elucidation of the mechanisms underlying the metastasis of solid tumors may improve patient outcomes, as the majority of cancer-associated mortalities are due to tumor progression and dissemination (1). Previous studies have investigated the role of immunity in tumor biology; however, the immune-mediated maintenance of tissue homeostasis (TH) in cancer has not been thoroughly explored (2-4). Tumor progression may be influenced by the immune system $(2,3)$. However, the role of tissue-specific factors in the outcome of adaptive immune responses remains unclear (4). Advances in molecular biology have allowed the investigation of the mechanisms involved in intercellular interactions. Consequently, there is an increased understanding of the factors involved in these interactions, allowing a comprehensive description of tissue development to be made. A number of immune cells, cytokines, growth factors and enzymes create a favorable microenvironment for maintaining a steady state in tissues $(5,6)$. However, which of these are essential in maintaining a favorable tissue microenvironment remains unknown. The interchange of signals at the tissue level is maintained by constant synthesis of various short-lived molecules, including cytokines, integrins and selectins, and exosomes $(7,8)$. TH is therefore a complex process. The present review attempted to analyze the functions of the immune system, not including its protective role against infection, and establish whether it has a morphogenetic or regulatory function in maintaining $\mathrm{TH}(9,10)$. Consequently, the present review focused on regulatory $\mathrm{T}$ cells, due to the tissue-specific manner these cells operate in $(11,12)$. Although $\mathrm{T}$ cells reside in tissues, they are functionally monitored by the thymus, and provide feedback on TH from the peripheral to the central immune system by their homing capacity (13). Elucidating the central immune regulation of tumor tissue 
evolution may aid in the development of novel immune therapies.

\section{Data sources and searches}

PubMed (www.ncbi.nlm.nih.gov/pubmed), Google Scholar (scholar.google.com), Scopus (www.scopus.com/home.uri) and Web of Science (login.webofknowledge.com) databases were searched in November 2017 using a combination of key words and text words related to 'solid tumor spread' and 'central immune regulation mechanisms' of this process. The search was not restricted by date. The main Medical Subject Headings in PubMed were as follows: i) Neoplasm/metastasis; ii) neoplasms/immunology; and iii) T-lymphocytes/immunology. The inclusion criteria were as follows: i) Peer-reviewed published articles; ii) original research articles; iii) reviews; iv) meeting abstracts; v) proceedings papers; and vi) book chapters containing information pertaining to the central immune regulation of tumor spread/metastasis. Documents that were not published in the public domain were excluded. A total of 90 articles which were selected by both authors were included in the current study. Disagreements were resolved through consensus.

\section{Central immune regulation in maintaining homeostasis of normal tissue}

The immune system detects pathogen invasion, fights against infection, prevents malignant transformations and contributes to permanent tissue renewal and remodeling following damage to the tissue $(10,14)$. The thymus is a central immune organ that serves a principal role in post-natal human life by maintaining the development and homeostasis of $\mathrm{T}$ cells $(15,16)$. The regenerative capacity of the thymus undergoes a significant decline in the postnatal period compared with its prenatal activity; however, it continues to perform a pivotal role in T-cell arrangement in adulthood (17). Stem cells of the thymic epithelium are constantly generated throughout the lifespan of a human and their pool is dynamically regulated by signals from the periphery in response to tissue requirements (18). The thymus generates clones of regulatory cells during the process of T-cell development, which occurs due to the recognition of self-antigens (19). Thymically derived regulatory cells (T-regs) are considered to serve important roles in maintaining and re-establishing of normal TH $(20,21)$. The immune system has a functional presence in every tissue and organ, as immune cells have the unique ability to travel between compartments (11). Each organ has a microenvironment that participates in feedback mechanisms in which dendritic cells present tissue major histocompatibility complex (MHC) antigens for recycling lymphocytes (22). The continuous recycling of lymphocytes from the blood into tissues is a highly sophisticated bi-directional process that reflects the homing capacity of migrating cells (19). The migrating lymphocytes patrol the tissues, thus maintaining homeostasis by a directional transfer of information, which is beneficial for tissue development $(7,10,23)$. The destination of the lymphocytes is predetermined by T-cell receptors (TCRs), which are located on the surface of migrating cells that interact with the appropriate ligands of high endothelium venules for penetration into the tissue (12). TCRs are designed to recognize different MHC molecules, which are presented by the majority of cells in the body (24). Using specific receptors, lymphocytes assess the antigenic immunity in body tissues, and the binding specificity of the TCRs is important in the process of recognition $(25,26)$. Consequently, the movement of lymphocytes into the lymphatic system and blood circulation, as well as their migration into the tissue, is an organized process (11). The endothelial cells of capillaries are not passive membranes that follow physical and chemical laws, rather they select for active traffic into tissues by target-binding to the receptor by antigen-antibody interaction (12). T-lymphocyte migration directed by TCRs is conducted by ligand-integrin interactions with adhesive molecules of blood vessel endothelium (27). Immune surveillance of peripheral tissues by $T$ cells is performed in response to homeostatic chemokines that are constitutively expressed in healthy tissues to recruit lymphoid cells in certain tissue sites (28).

Tissue disturbance due to injury or inflammation results in the secretion of cytokines, triggering the hyperactive expression of specific integrins on the surface of endothelial cells. The lymphocytes connected to the integrins adhere to the endothelium, enter between adjacent endothelial cells and exit the bloodstream (27). Simultaneously, lymphocytes, macrophages and other lymphoid cells, including neutrophils and monocytes, penetrate through the intercellular gaps and re-enter the circulation. Lymphatic tissue is constantly renewing its cell population in order to continuously recycle lymphocytes $(14,29)$. Recirculating lymphocytes are a major part of the population of small lymphocytes, the majority of which are T-lymphocytes (30). T-lymphocytes are characterized by their rapid migration, which enables them to constantly move between the blood and peripheral organs $(31,32)$. As such, small lymphocytes are an extremely mobile cell population. Due to their mobility, lymphocytes are able to penetrate into intercellular spaces (33). Subsequent to passing through the vessel endothelium, lymphocytes may interact with intercellular matrix proteins and tissue cells. The complex interactions among lymphocytes, residing immune cells, stromal components and tissue-specific factors influence the outcome of the immune responses at the tissue level (14). As a result, all functioning tissues have active lymphocytes located around postcapillary venules $(11,34)$. The zone of interaction between endothelial cells, lymphocytes and tissue structures is termed the immune regulatory zone, or the immune regulatory compartment of an organ $(34,35)$. Previous studies demonstrated that the majority of tissue lymphocytes are T-lymphocytes, which originate from the double-positive helper/suppressor population, and are currently defined as the regulatory population $(13,36)$. Through a homing mechanism, T-lymphocytes undergo a settling stage in the tissue, where they acquire their immunological specificity (11).

The thymus is an important site for the development of T-regs during the positive selection process of clones that are tailored to the tissue in which they complete differentiation (37). Following this process, T-regs join the lymphatic system and blood circulation. Circulating lymphocytes form a pool of cells carrying receptors that are specific for the particular tissues that created this clone (11). Once the migration process has started, a functional complex that includes an adjustable tissue 

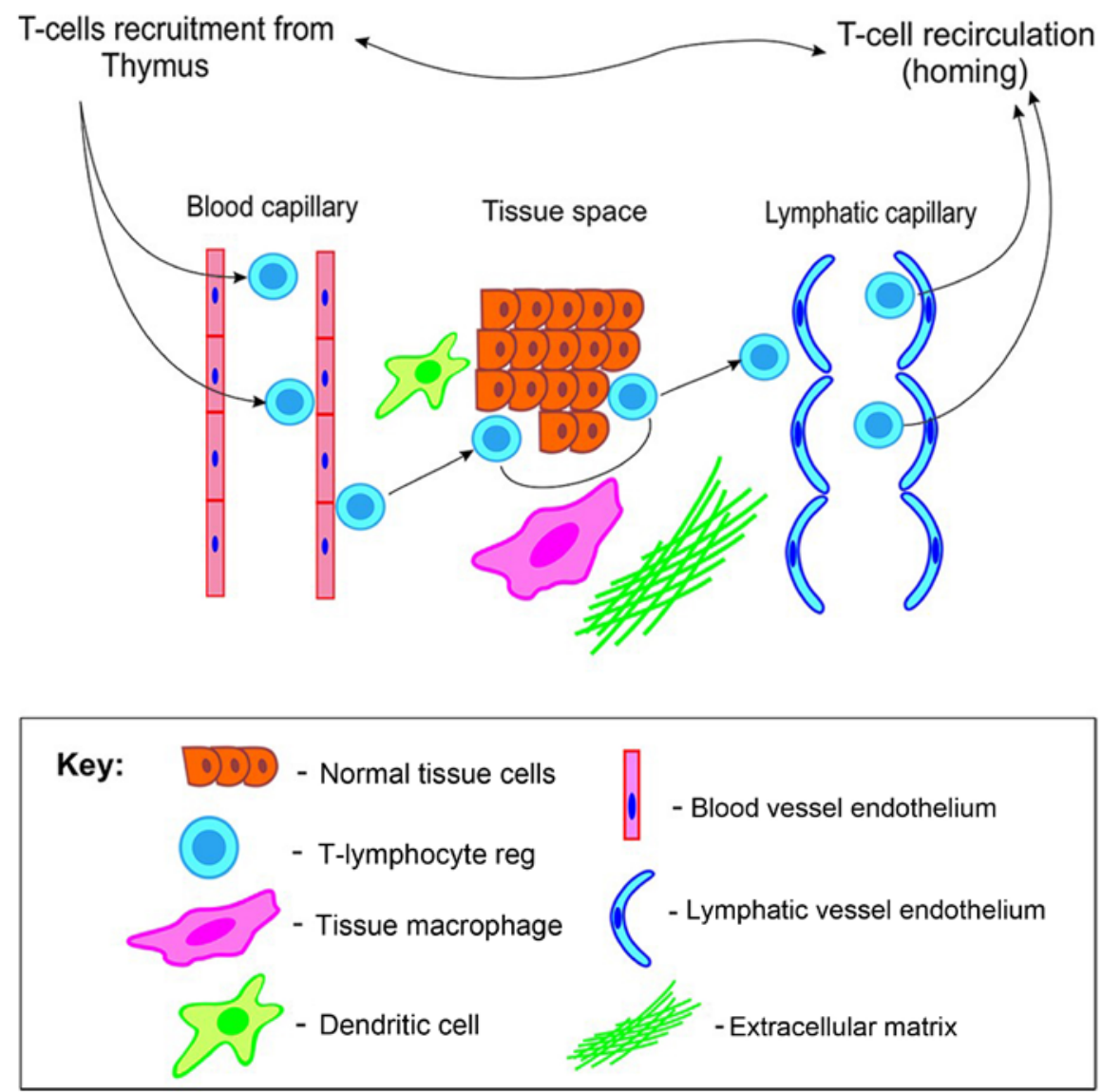

Figure 1. Principal components of immune regulatory compartments in functioning tissue. This diagram illustrates that any functioning tissue is a highly organized peripheral division of the immune system with a stable contingent of residing components (tissue macrophages, dendritic cells, extracellular matrix) and a mobile component (recycling regulatory T-cells that are functionally monitored by the thymus).

and regional lymph nodes is formed. It provides a selectivity of migration, termed homing (12). Such selectivity is associated with effector lymphocytes acquiring novel properties dictated by the local tissue microenvironment $(38,39)$. Therefore, any regenerating/renewing healthy tissue that is non-inflamed drives the preferential recruitment of a highly restricted repertoire of specific T-regs for its continued development (13).

One issue that remains is concerned with the manner in which recirculating T-cells perform the morphogenetic functions of the immune system. Cell-to-cell interactions assist multicellular organisms to function as a stable system (40). Informational support by the transfer of genetic material in the form of exosomes to developing tissue is an immunoediting function of T-cells (41), although the transmission mechanism of information pertaining to regeneration has not been fully elucidated. Previous studies have indicated that cells can communicate via the direct exchange of genetic patterns in the form of exosomes and apoptotic bodies $(7,40,42)$. The processes of cell-to-cell communications via exosomes are a potential driving factor of phenotypic changes and cellular plasticity during tissue regeneration (43). Therefore, specific genetic messages are designed to be embedded into accepting cells for their differentiation with subsequent tissue development. The required level of exosomes is provided by cell activation and apoptosis, which underlies the effector mechanisms of immune cell action (44). The genetic information contained within exosomes in the form of DNA or RNA can influence the target cell by triggering activation, differentiation or even by promoting apoptosis (40). In the immune system, exosomes from $\mathrm{T}$ cells can directly fuse with accepted tissue cells, releasing relevant functional information (45). The involvement of lymphocytes in the regulation of tissue development has clearly been demonstrated by their presence in the microenvironment of differentiating hematopoietic cells of the bone marrow (46). Furthermore, T-regs have been shown to serve an important role in maintaining the homeostasis of skin and various mucosal surfaces, from which epithelial tumors have been identified to form $(13,47)$.

In summary, any functioning tissue is a highly organized peripheral division of the immune system with a stable contingent of residing cells and a mobile component comprised of recycling regulatory $\mathrm{T}$ cells that are functionally monitored by the thymus. These $\mathrm{T}$ cells provide a feedback reaction to the thymus as a central part of the immune system. T-regs actively participate in the generation of adaptive immune responses. The processes of the migration and recirculation of immune cells, and their active interactions with other tissue structures ensure the maintenance of TH (Fig. 1).

\section{Immune regulation in case of tumor tissue manifestation and metastatic spread}

One topic of note is what happens to the highly sophisticated hierarchy of $\mathrm{TH}$ regulation in the extreme case of its imbalance, 
i.e., during malignant transformation of tissue. Since tumor cells originate from normal ones, the key principles of immune regulation are preserved in the transformed tissue. Therefore, immune mechanisms that regulate tumor tissue function may be the same as in cases of normal non-metastatic tissues (48).

When tumors develop, the new tissue evolves and the metastatic potential of the rapidly dividing cells (cellular clones) constantly increases. Clinically, metastasis is the last stage of tumor progression. Prior studies revealed that the process of cancer spreading is not random, and follows domestic rules and mechanisms in the 'host-tumor' system (49-51). This was confirmed when certain cancer types elected to metastasize over their preferred target tissues (52). Previous studies have provided supporting evidence of the importance a common mechanism involved in the regulation of tumor progression: i) Tumor cells acquire metastatic properties prior to migration from the site of the primary tumor (53); ii) the systemic circulation of tumor cells may subsequently remain latent for an extended period of time (54) and the presence of tumor cells in the blood is not indicative of metastasis $(55,56)$; iii) the formation of metastatic niches in the form of restructured stroma in tissues distant from the site of the primary tumor begins prior to the dissemination of malignant cells $(2,57)$; and iv) the enhanced vascularization of blood and lymph vessels in tumors contributes to the process of metastasis $(58,59)$. Clonal polymorphism, genetic instability of tumor cells and a hypoxic microenvironment contribute to the expression of multiple angiogenic factors in malignant tissues (60-62). Nevertheless, it has been postulated that stimulation of vessel growth in tumors occurs via the same mechanism as that in normal tissue (63). As such, blood vessels treat the tumor as an extra cell mass, which requires nutrition and elimination of the products of tissue metabolism (64). The aforementioned process supports the hypothesis that the influence of the host on the formation of the tumor microenvironment is a factor that determines when the metastatic process is initiated as the formation of metastatic niches begins before the spread of malignant cells, and neoangiogenesis contributes to the process of metastasis. However, the central regulatory mechanisms that activate selected tumor cells for metastatic initiation remain poorly defined.

T-regs with the phenotype cluster of differentiation (CD) $4^{+} \mathrm{CD} 25^{+}$forkhead box $\mathrm{P}^{+}\left(\mathrm{FOXP}^{+}\right)$imitate mediators of immune editing (surveillance) (65-67). Novel immune checkpoint inhibitors recognize that T-regs serve a key role in tumor development (68). Therefore, elucidating the associations of T-regs and tumor cells may provide insight into the modulation of the host response to the malignant transformation of tissues (66). T-reg density within tumor lesions and the recurrent imbalance of its contents in the blood has been associated with the clinical outcome of patients in a number of types of cancer, including breast, cervical, endometrial, ovarian, colorectal and pancreatic cancer (69-71). Tumor-specific T-regs may originate in the thymus during T-cell development and are recruited to the tumor lesion in a preferential manner from the diverse systemic pool of T-regs $(19,48)$.

The phenotype, differentiation status and function of regulatory immune cells depend on the anatomical compartment in which the cells reside. Even immune cells that originated from the same precursors, but which reside in different tissues, have diverse functions as they are instructed by different, organ-specific factors (11). Consequently, different types of tissue have different antigens that activate the immune system and generate regional immune responses, which is associated with the relative stability of the tissue. In cases of tumor transformation due to immune escape mechanisms, the immune system may maintain homeostasis in the newly-formed anatomical site, i.e., the tumor. Therefore, the immune system allows the tumor to grow rather than destroy it $(65,72)$, suggesting a mechanism of how tumor tissue development, and progression may coexist with the normal function of an organ $(2,64)$. Tumor cells are constantly exposed to immune cells during each phase of the metastatic process, suggesting that the immune cells may restrict their development (73). However, previous studies have revealed that tumor-infiltrating immune cells may instead promote the metastatic cascade $(2,3,72)$. T-regs may serve a role in increasing the number of surviving tumor cells in circulation and metastatic sites; however, the precise mechanisms underlying this process remain unknown (2).

The thymus orchestrates the arrangement of T-cell clones and predetermines the function of T-cell populations on the periphery $(27,74)$. A prior study that observed changes in the thymus during experimental carcinogenesis revealed that the development of malignant tumors in the colons of rats was correlated with significant fluctuations in the morphology of the thymus, highlighting the role of central immunological regulation in tumor biology (75). These variations were manifested in the differentiation and apoptosis of thymus cells, as well as changes to the components in the microenvironment of the thymus cells. Notably, significant transformations in the thymus, including an increase in the number of thymic cells, active T-lymphocytes and changes in the microenvironment were observed during the precancerous stage in the intestinal mucosa (75). The aforementioned study reported that colonic cancer had a greater impact on the thymus morphology. It manifested in the elevation of proliferation and differentiation of thymocytes into mature forms with their subsequent traffic to the colonic mucosa (75). Experimental data regarding the increased egress of mature thymocytes and their migration into peripheral circulation are consistent with clinical data reporting an increased T-reg lymphocyte population in the peripheral blood of patients with solid tumors including melanoma and breast, lung, gastric, ovarian, head and neck, tumors $(65,70,76)$. Furthermore, T-reg lymphocytes have been detected in lymph nodes containing micrometastases, but not in healthy lymph nodes (77). The detection of T-reg lymphocytes and the formation of new lymphatic vessels precede the detection of metastatic lesions in the regional lymph nodes (78). T-lymphocyte clones migrate and infiltrate a solid tumor (70). According to numerous studies, they are mainly represented by the same regulatory thymic subpopulation of lymphocytes, which has been discussed previously $(48,79,80)$.

The process of malignant transformation of tissue is accompanied by the formation of T-lymphocyte clones designed for that tissue. These lymphocytes begin to differentiate in the thymus and complete the differentiation process in the tumor tissue, which is actively involved in the generation of immune signals required to maintain tissue development (81). Consequently, the tumor tissue may be considered as a peripheral compartment of the immune system whose 


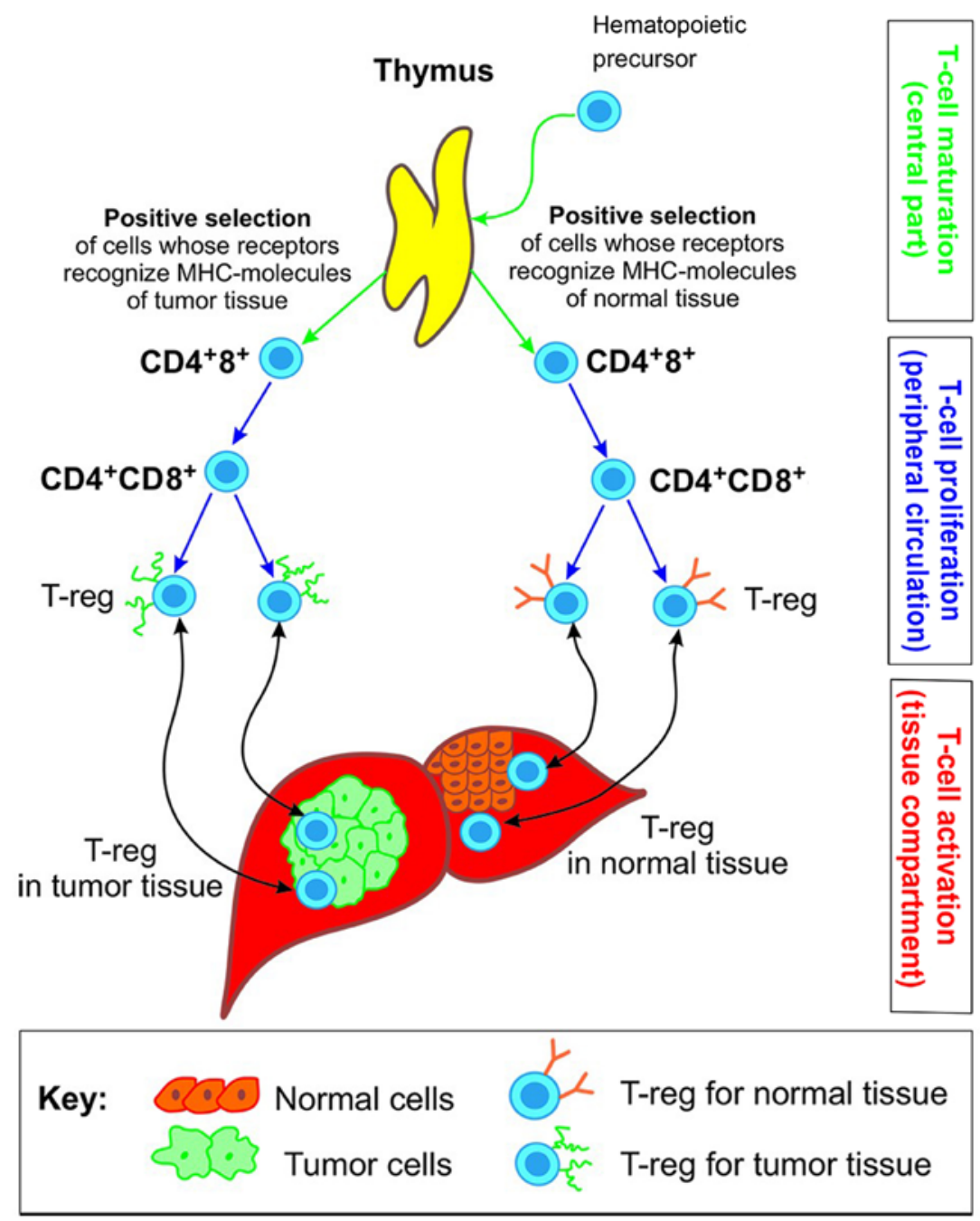

Figure 2. Schematic of the central immune regulation of homeostasis in normal and tumor tissue in the case of clinical tumor manifestation. Lymphocytes begin to differentiate in the thymus and complete their differentiation at the periphery tissue compartment where they migrate due to their homing capacity. As a result, the organ affected by the tumor consists of tumor and normal tissues infiltrated by T-reg lymphocytes designed for the particular tissue type. These clones are similar in their T-reg phenotype and differ only in the direction of migration to the appropriate tissue which is dictated by unique set of MHC-antigens. T-reg, thymically derived regulatory cell; MHC, major histocompatibility complex; $\mathrm{CD}$, cluster of differentiation.

regulatory zone includes vessels, endothelial cells, circulating and settled pools of T-reg lymphocytes, tumor cells and components of the extracellular matrix. Therefore, the affected organ consists of tumor and normal tissues. Each of these tissue types has a zone infiltrated by T-reg lymphocytes designed for this tissue type. There are clones for tumor and normal tissues in the peripheral circulation of an organism with cancer. Phenotypically these clones are similar, all being T-reg $\mathrm{CD}^{+}{ }^{+} \mathrm{FOXP}^{+}$cells $(79,82)$. However, they differ in the direction of migration to the appropriate tissue, which expresses its own unique set of histocompatible antigens (Fig. 2).

An increased number of T-regs in tumor tissues is associated with a higher degree of differentiation and an improved prognosis (69-71,76), suggesting that T-regs serve a role in the pace of tumor progression. A previous study in patients with breast cancer assessed T-reg lymphocytes profiles in samples of tumor tissue following the administration of neo-adjuvant chemotherapy, and a significant reduction in T-regs among infiltrating tumor tissue lymphocytes was detected (83). This suggests the possibility of using T-reg lymphocytes as a prognostic marker for response to chemotherapy and demonstrates a direct association between tumor regression and a reduction in the population of T-reg lymphocytes $(70,84,85)$.

Novel immunotherapies may have a greater impact on T-reg lymphocyte subpopulations than traditional chemotherapy agents $(68,86)$. The clinical application of targeted antitumor drugs against cytotoxic T-lymphocyte associated protein 4 and programmed cell death 1 lymphocyte receptors, termed immune checkpoint inhibitors, has demonstrated efficacy in a subset of patients with aggressive solid tumors, including disseminated melanoma, renal cell carcinoma and non-small cell lung cancer $(86,87)$. Furthermore, patients demonstrated partial or complete tumor regression following the administration of the aforementioned immune therapies, which persisted following the cessation of therapy, which was renewed as an identical treatment if disease progression occurred (87). Novel immunotherapies have increased the potential available targets of anticancer drugs, providing insights into the mechanisms underlying tumor development and progression. Preceding studies have identified novel agents that target lymphocytes and alter the immunological microenvironment 
of tumors, thus promoting tolerance and changes to the apoptotic program in tumor tissues $(81,88,89)$. Tolerance may be considered as the deprivation of the informational support from the host to the tumor (90). This data implicates T-regs in the process of tumor progression and the presence of central immune mechanisms that govern tumor spread $(2,3)$. In spite of the fact that the tumor promoting role of tumor-infiltrating immune cells at each step of the metastatic cascade has been stated,interactions between tumor and immune cells are traditionally considered in the context of tolerance or suppression by the immune system only at the tissue level without the evaluation of central, i.e. thymic, regulation of immune cell behavior $(2,3,88)$. Previous studies investigating malignant tissue revealed central mechanisms of immune regulation that define the character, direction and outcomes of cellular interactions at the tissue level $(2,48)$. As this novel therapeutic strategy with checkpoint inhibitors has demonstrated, a functional blockade of the lymphocytes regulating homeostasis in tumor tissue leads to tumor regression due to the deprivation of immunological support from the host $(86,90)$. Therefore, there is a requirement for selective therapeutic agents that target the population of tumor-associated T-regs and not other T-regs in the body.

\section{Conclusion}

The current review summarizes the data on the participation of the immune system in the process of tumor growth and metastatic spread. Previous studies have demonstrated the importance of the role of recirculating and tissue-residing immunocompetent cells in tumor progression. However, even a detailed phenotypic specification of lymphoid cells and analysis of their interactions does not completely describe the tumor spread regulation without considering the central part of T-cell competency formation. Central regulation mechanisms provide insight into the predestination and direction of immune reactions in tumor tissue. We believe that enough data pertaining to the regulatory levels of tumor metastasis is available to attempt to influence the process of tumor spread globally, by changing the speed and direction through therapies that target not only tumor cells, but also the regulatory mechanisms of the immune system. For example, the targeted impact on the adaptive immune response with immune checkpoint inhibitors is a successful strategy in immune system interventions in patients with cancer. Finally, elucidating the mechanisms of tumor metastasis with regard to immunological regulation may aid the identification and development of novel therapeutic strategies. A limitation of the present review is that it is purely narrative. Insight into the process of tumor spread through the prism of central immune regulation may be of interest to clinicians, and an in-depth explanation of the mechanisms underlying the efficiency and toxicity of novel immune therapies with checkpoint inhibitors is a topic for future research.

\section{Acknowledgements}

Not applicable.

\section{Funding}

No funding was received.

\section{Availability of data and materials}

Not applicable.

\section{Authors' contributions}

NL conceived the study. NS critically revised the manuscript and contributed to the editing process. The two authors read and approved the final manuscript.

\section{Ethics approval and consent to participate}

Not applicable.

\section{Patient consent for publication}

Not applicable.

\section{Competing interests}

The authors declare that they have no competing interests.

\section{References}

1. Jiang WG and Ablin RJ: Cancer metastasis, challenges, progress and the opportunities. Front Biosci (Elite Ed) 3: 391-394, 2011.

2. Kitamura T, Qian BZ and Pollard JW: Immune cell promotion of metastasis. Nat Rev Immunol 15: 73-86, 2015.

3. Smith HA and Kang YT: The metastasis-promoting roles of tumor-associated immune cells. J Mol Med (Berl) 91: 411-429, 2013.

4. Fridman WH, Pages F, Sautes-Fridman C and Galon J: The immune contexture in human tumours: Impact on clinical outcome. Nat Rev Cancer 12: 298-306, 2012.

5. Zlotnic A and Yoshie O: The chemokine superfamily revisited. Immunity 36: 705-716, 2012.

6. Almeida FF and Belz GT: Innate lymphoid cells: Models of plasticity for immune homeostasis and rapid responsiveness in protection. Mucosal Immunol 9: 1103-1112, 2016.

7. Corrado C, Raimondo S, Chiesi A, Ciccia F, De Leo G and Alessandro R: Exosomes as intercellular signaling organelles involved in health and disease: Basic science and clinical applications. Int J Mol Sci 14: 5338-5366, 2013.

8. Wang CM, Ploia C, Anselmi F, Sarukhan A and Viola A: Adenosine triphosphate acts as a paracrine signaling molecule to reduce the motility of T cells. EMBO J 33: 1354-1364, 2014.

9. Fidler IJ: Lymphocytes are not only immunocytes. Biomedicine 32: 1-3, 1980.

10. Senovilla L, Galluzzi L, Zitvogel L and Kroemer G: Immunosurveillance as a regulator of tissue homeostasis. Trends Immunol 34: 471-481, 2013.

11. Hu W and Pasare C: Location, location, location: Tissue-specific regulation of immune responses. J Leukoc Biol 94: 409-421, 2013.

12. Shechter R, London A and Schwartz M: Orchestrated leukocyte recruitment to immune-privileged sites: Absolute barriers versus educational gates. Nat Rev Immunol 13: 206-218, 2013.

13. Schaerli P, Ebert L, Willimann K, Blaser A, Roos RS, Loetscher P and Moser B: A skin-selective homing mechanism for human immune surveillance T cells. J Exp Med 199: 1265-1275, 2004.

14. Satija R and Shalek AK: Heterogeneity in immune responses: From populations to single cells. Trends Immunol 35: 219-229, 2014.

15. Caramalho I, Nunes-Cabaco H, Foxall RB and Sousa AE: Regulatory T-cell development in the human thymus. Front Immunol 6: 395, 2015.

16. Ge Q, Hu H, Eisen HN and Chen J: Different contributions of thymopoiesis and homeostasis-driven proliferation to the reconstitution of naive and memory T cell compartments. Proc Natl Acad Sci USA 99: 2989-2994, 2002. 
17. Chinn IK, Blackburn CC, Manley NR and Semprowski GD Changes in primary lymphoid organs with aging. Semin Immunol 24: 309-320, 2012.

18. Ucar O, Li K, Dvornicov D, Kreutz C, Timmer J, Matt S, Brenner L, Smedley S, Travis MA, Hoffman TG, et al: A thymic epithelial stem cell pool persists throughout ontogeny and is modulated by TGF- $\beta$. Cell Rep 17: 448-457, 2016.

19. Hsieh CS, Lee HM and Lio CW: Selection of regulatory T cells in the thymus. Nat Rev Immunol 12: 157-567, 2012.

20. Dobrzanski MJ: Expanding roles for CD4 T cells and their subpopulations in tumor immunity and therapy. Front Oncol 3 : 63, 2013.

21. von Boehmer $\mathrm{H}$ : The thymus in immunity and in malignancy. Cancer Immunol Res 2: 592-597, 2014.

22. Dong J, Chen Y, Xu X, Jin R, Teng F, Yan F, Tang H, Li P, Sun X, Li Y, et al: Homeostatic properties and phenotypic maturation of murine $\mathrm{CD}^{+}$pre-thymic emigrants in the thymus. PLoS One 8 : e56378, 2013.

23. Munoz MA, Biro M and Weninger W: $\mathrm{T}$ cell migration in intact lymph nodes in vivo. Curr Opin Cell Biol 30: 17-24, 2014.

24. Singh NK, Riley TP, Baker SCB, Borrman T, Weng Z and Baker BM: Emerging concepts in TCR specificity: Rationalizing and (maybe) predicting outcomes. J Immunol 199: 2203-2213, 2017.

25. Parrish HL, Deshpande NR, Vasic J and Kuhns MS: Functional evidence for TCR-intrinsic specificity for MHCII. Proct Natl Acad Sci USA 113: 3000-3005, 2016.

26. Sethna Z, Elhanati Y, Dudgeon CS, Callan CG Jr, Levine AJ, Mora T and Walczak AM: Insights into immune system development and function from mouse T-cell repertoires. Proc Natl Acad Sci USA 114: 2253-2258, 2017.

27. Muller WA: How endothelial cells regulate transmigration of leukocytes in the inflammatory response. Am J Pathol 184 886-896, 2014

28. Anders HJ, Romagnani P and Mantovani A: Pathomechanisms: Homeostatic chemokines in health, tissue regeneration, and progressive diseases. Trends Mol Med 20: 154-165, 2014.

29. Thiault N, Darrigues J, Adoue V, Gros M, Binet B, Perals C, Leobon B, Fazilleau N, Joffre OP, Robey EA, et al: Periphera regulatory $\mathrm{T}$ lymphocytes recirculating to the thymus suppress the development of their precursors. Nat Immunol 16: 628-634, 2015.

30. Farber DL, Yudanin NA and Restifo NP: Human memory T cells: Generation, compartmentalization and homeostasis. Nat Rev Immunol 14: 24-35, 2014.

31. Halkias J, Melichar HJ, Taylor KT and Robey EA: Tracking migration during human $\mathrm{T}$ cell development. Cell Mol Life Sci 71: 3101-3117, 2014

32. Dominguez GA, Anderson NR and Hammer DA: The direction of migration of T-lymphocytes under flow depends upon which adhesion receptors are engaged. Integr Biol (Camb) 7: 345-355, 2015.

33. Mrass P, Petravic J, Davenport MP and Weninger W: Cell-autonomous and environmental contributions to the interstitial migration of T cells. Semin Immunopathol 32: 257-274, 2010

34. Ruddle NH: Lymphatic vessels and tertiary lymphoid organs. J Clin Invest 124: 953-959, 2014.

35. Mai J, Virtue A, Shen J, Wang H and Yang XF: An evolving new paradigm: Endothelial cells-conditional innate immune cells J Hematol Oncol 6: 61, 2013.

36. Smigiel KS, Srivastava S, Stolley JM and Campbell DJ: Regulatory T-cell homeostasis: Steady-state maintenance and modulation during inflammation. Immunol Rev 259: 40-59, 2014.

37. Feinerman O, Jentsch G, Tkach KE, Coward JW, Hathorn MM, Sneddon MW, Emonet T, Smith KA and Altan-Bonnet G: Single-cell quantification of IL-2 response by effector and regulatory $\mathrm{T}$ cells reveals critical plasticity in immune response. Mol Syst Biol 6: 437, 2010

38. Barbi J, Pardoll D and Pan F: Treg functional stability and its responsiveness to the microenvironment. Immunol Rev 259: $115-139,2014$

39. Zhan Y, Bourges D, Dromey JA, Harrison LC and Lew AM: The origin of thymic $\mathrm{CD} 4{ }^{+} \mathrm{CD} 25^{+}$regulatory $\mathrm{T}$ cells and their co-stimulatory requirements are determined after elimination of recirculating peripheral $\mathrm{CD}^{+}{ }^{+}$cells. Int Immunol 19: 455-463, 2007.

40. Mittelbrunn M and Sánchez-Madrid F: Intercellular communication: Diverse structures for exchange of genetic information. Nat Rev Mol Cell Biol 13: 328-335, 2012.
41. Mittelbrunn M, Gutierrez-Vazquez C, Villarroya-Beltri C, Gonzalez S, Sanchez-Cabo F, González MÁ Bernad A and Sanchez-Madrid F: Unidirectional transfer of microRNA-loaded exosomes from $\mathrm{T}$ cells to antigen-presenting cells. Nat Commune 2: 282, 2011.

42. Azmi AS, Bao B and Sarkar FH: Exosomes in cancer development, metastasis, and drug resistance: A comprehensive review. Cancer Metastasis Rev 32: 623-642, 2013.

43. Yáñez-Mó M, Siljander PR, Andreu Z, Zavec AB, Borràs FE, Buzas EI, Buzas K, Casal E, Cappello F, Carvalho J, et al: Biological properties of extracellular vesicles and their physiological functions. J Extracell Vesicles 4: 27066, 2015.

44. Green DR, Droin N and Pinkoski M: Activation-induced cell death in T cells. Immunol Rev 193: 70-81, 2003.

45. Ventimiglia LN and Alonso MA: Biogenesis and function of T cell-derived exosomes. Front Cell Dev Biol 4: 84, 2016.

46. Tang Q, Jiang D, Harfuddin Z, Cheng K, Moh MC and Schwarz H: Regulation of myelopoiesis by CD137L signaling. Int Rev Immunol 33: 454-469, 2014.

47. Medler TR and Coussens LM: Duality of the immune response in cancer: Lessons learned from skin. J Invest Dermatol 134: E23-E28, 2014

48. Savage PA, Leventhal DS and Malchow S: Shaping the repertoire of tumor-infiltrating effector and regulatory $\mathrm{T}$ cells. Immunol Rev 259: 245-258, 2014

49. Seyfried TN and Huysentruyt LC: On the origin of cancer metastasis. Crit Rev Oncog 18: 43-73, 2013.

50. Keskinov AA and Shurin MR: Myeloid regulatory cells in tumor spreading and metastasis. Immunobiology 220: 236-242, 2015.

51. Kovács KA, Hegedus B, Kenessey I and Tímár J: Tumor type-specific and skin region-selective metastasis of human cancers: Another example of the 'seed and soil' hypothesis. Cancer Metastasis Rev 32: 493-499, 2013.

52. Ben-Baruch A: Organ selectivity in metastasis: Regulation by chemokines and their receptors. Clin Exp Metastasis 25: 345-356, 2008.

53. Satelli A, Mitra A, Brownlee Z, Xia X, Bellister S, Overman MJ, Kopetz S, Ellis LM, Meng QH and Li S: Epithelial-mesenchymal transitioned circulating tumor cells capture for detecting tumor progression. Clin Cancer Res 21: 899-906, 2015.

54. Dasgupta A, Lim AR and Ghajar CM: Circulating and disseminated tumor cells: Harbingers or initiators of metastasis? Mol Oncol 11: 40-61, 2017.

55. Caceres G, Puskas JA and Magliocco AM: Circulating tumor cells: A window into tumor development and therapeutic effectiveness. Cancer Control 22: 167-176, 2015.

56. Caixeiro NJ, Kienzle N, Lim SH, Spring KJ, Tognela A, Scott KF, de Souza P and Becker TM: Circulating tumour cells-a bona fide cause of metastatic cancer. Cancer Metastasis Rev 33: 747-756, 2014.

57. Sceneay J, Smyth MJ and Möller A: The pre-metastatic niche: Finding common ground. Cancer Metastasis Rev 32: 449-464, 2013.

58. Paduch R: The role of lymphangiogenesis and angiogenesis in tumor metastasis. Cell Oncol (Dordr) 39: 397-410, 2016.

59. Coso S, Bovay E and Petrova TV: Pressing the right buttons Signaling in lymphangiogenesis. Blood 123: 2614-2624, 2014

60. Pietras K and Östman A: Hallmarks of cancer: Interactions with the tumor stroma. Exp Cell Res 316: 1324-1331, 2010.

61. Spano D and Zollo M: Tumor microenvironment: A main actor in the metastasis process. Clin Exp Metastasis 29: 381-395, 2012

62. Spinella F, Caprara V, Cianfrocca R, Rosanò L, Di Castro V, Garrafa E, Natali PG and Bagnato A: The interplay between hypoxia, endothelial and melanoma cells regulates vascularization and cell motility through endothelin-1 and vascular endothelial growth factor. Carcinogenesis 35: 840-848, 2014

63. Re RN and Cook JL: An intracrine view of angiogenesis. Bioessays 28: 943-953, 2006.

64. Egeblad M, Nakasone ES and Werb Z: Tumors as organs: Complex tissues that interface with the entire organism. Dev Cell 18: 884-901, 2010.

65. Wolf D, Sopper S, Pircher A, Gastl G and Wolf AM: Treg(s) in cancer: Friends or foe? J Cell Physiol 230: 2598-2605, 2015.

66. Nishikawa $\mathrm{H}$ and Sakaguchi S: Regulatory $\mathrm{T}$ cells in tumor immunity. Int J Cancer 127: 759-767, 2010.

67. Bhatia A and Kumar Y: Cellular and molecular mechanisms in cancer immune escape: A comprehensive review. Expert Rev Clin Immunol 10: 41-62, 2014.

68. Dyck L and Mills KHG: Immune checkpoints and their inhibition in cancer and infectious diseases. Eur J Immunol 47: 765-779, 2017. 
69. Curiel TJ: Regulatory T cells and treatment of cancer. Curr Opin Immunol 20: 241-246, 2008.

70. deLeeuw RJ, Kost SE, Kakal JA and Nelson BH: The prognostic value of FoxP $3^{+}$tumor-infiltrating lymphocytes in cancer: A critical review of the literature. Clin Cancer Res 18: 3022-3029, 2012.

71. Mailloux AW and Young MR: Regulatory T-cell trafficking: From thymic development to tumor-induced immune suppression. Crit Rev Immunol 30: 435-447, 2010.

72. De Visser KE, Eichten A and Coussens LM: Paradoxical roles of the immune system during cancer development. Nat Rev Cancer 6: 24-37, 2006.

73. Quail DF and Joyce JA: Microenvironmental regulation of tumor progression and metastasis. Nat Med 19: 1423-1437, 2013.

74. Josefowicz SZ, Lu LF and Rudensky AY: Regulatory T cells: Mechanisms of differentiation and function. Annu Rev Immunol 30: 531-564, 2012.

75. Struchko GY,Merkulova LM and Moskvichev YV: Morphological and immunohistochemical characteristics of the thymus during chemical carcinogenesis induced by 1,2-dimethylhydrazine administration. Morfologiia 146: 35-39, 2014 (In Russian).

76. Hamidinia M, Ghafourian Boroujerdnia M, Talaiezadeh A, Solgi G, Roshani R, Iranprast S and Khodadadi A: Increased P-35, EBI3 transcripts and other Treg markers in peripheral blood mononuclear cells of breast cancer patients with different clinical stages. Adv Pharm Bull 5: 261-267, 2015.

77. Lee JH, Chen Y, Chan JL, Qian YW and Goydos JS: Molecular analysis of melanoma-induced sentinel lymph node immune dysfunction. Cancer Immunol Immunother 60: 685-692, 2011.

78. Lagios MD: Clinical significance of immunohistochemically detectable epithelial cells in sentinel lymph node and bone marrow in breast cancer. J Surg Oncol 83: 1-4, 2003.

79. Vasco C, Canazza A, Rizzo A, Mossa A, Corsini E, Silvani A, Fariselli L, Salmaggi A and Ciusani E: Circulating T regulatory cells migration and phenotype in glioblastoma patients: An in vitro study. J Neurooncol 115: 353-363, 2013.

80. Zhang X, Kelaria S, Kerstetter J and Wang J: The functional and prognostic implications of regulatory $\mathrm{T}$ cells in colorectal carcinoma. J Gastrointest Oncol 6: 307-313, 2015.
81. Protti MP, De Monte L and Di Lullo G: Tumor antigen-specific $\mathrm{CD} 4^{+} \mathrm{T}$ cells in cancer immunity: From antigen identification to tumor prognosis and development of therapeutic strategies. Tissue Antigens 83: 237-246, 2014.

82. Chen X and Oppenheim JJ: Resolving the identity myth: Key markers of functional $\mathrm{CD}^{+}{ }^{+} \mathrm{FoxP} 3^{+}$regulatory $\mathrm{T}$ cells. Int Immunopharmacol 11: 1489-1496, 2011.

83. Ladoire S, Arnould L, Apetoh L, Coudert B, Martin F, Chauffert B, Fumoleau P and Ghiringhelli F: Pathologic complete response to neoadjuvant chemotherapy of breast carcinoma is associated with the disappearance of tumor-infiltrating Foxp $3^{+}$regulatory T cells. Clin Cancer Res 14: 2413-2420, 2008.

84. Teng MW, Ngiow SF, von Scheidt B, McLaughlin N, Sparwasser T and Smyth MJ: Conditional regulatory T-cell depletion releases adaptive immunity preventing carcinogenesis and suppressing established tumor growth. Cancer Res 70: 7800-7809, 2010.

85. Liu Y, Gu Y and Cao X: The exosomes in tumor immunity. Oncoimmunology 4: e1027472, 2015.

86. Bersanelli $\mathrm{M}$ and Buti S: From targeting the tumor to targeting the immune system: Transversal challenges in oncology with the inhibition of the PD-1/PD-L1 axis. World J Clin Oncol 8: 37-53, 2017.

87. Dolan DE and Gupta S: PD-1 pathway inhibitors: Changing the landscape of cancer immunotherapy. Cancer Control 21: 231-237, 2014.

88. Rei M, Pennington DJ and Silva-Santos B: The emerging protumor role of $\gamma \delta \mathrm{T}$ lymphocytes: Implications for cancer immunotherapy. Cancer Res 75: 798-802, 2015.

89. Pennock GK and Chow LQ: The evolving role of immune checkpoint inhibitors in cancer treatment. Oncologist 20: 812-822, 2015.

90. Zhu J, Powis de Tenbossche CG, Cane S, Colau D, van Baren N, Lurquin C, Schmitt-Verhulst AM, Liljestrom P, Uyttenhove C and Van den Eynde BJ: Resistance to cancer immunotherapy mediated by apoptosis of tumor-infiltrating lymphocytes. Nat Commun 8: 1404, 2017.

This work is licensed under a Creative Commons Attribution-NonCommercial-NoDerivatives 4.0 International (CC BY-NC-ND 4.0) License. 